\title{
Cloverleaf Skull and Thanatophoric Dwarfism
}

\section{Report of Four Cases, Two in the Same Sibship}

\author{
M. W. PARTINGTON, F. GONZALES-CRUSSI, S. G. KHAKEE, and D. G. WOLLIN \\ From Derbyshire Children's Hospital, Derby, England; and the Departments of Paediatrics, Pathology and Radiology \\ Queen's University, Kingston, Ontario, Canada
}

Partington, M. W., Gonzales-Crussi, F., Khakee, S. G., and Wollin, D. G. (1971). Archives of Disease in Childhood, 46, 656. Cloverleaf skull and thanatophoric dwarfism: report of four cases, two in the same sibship. Four cases of the cloverleaf skull syndrome are reported, 3 from Britain and 1 from Canada in a family of German/Irish descent. All cases had generalized chondrodysplastic changes and died at or just after birth. It is suggested that a cloverleaf skull is a previously unrecognized feature of thanatophoric dwarfism. Two affected girls from the same sibship are reported for the first time, suggesting an autosomal recessive type of inheritance.

A review of the published material indicates that there may be three distinct syndromes in patients with the cloverleaf skull deformity. (1) The cloverleaf skull is associated with thanatophoric dwarfism and death in the perinatal period. (2) There are localized bony lesions of the skeleton outside the skull. (3) The skeleton outside the skull is normal. In the last two syndromes death may occur at birth, but survival into later childhood is the rule.

The cloverleaf skull or Kleeblattschädel is a congenitally enlarged and trilobed skull. There are now over 20 published cases, most of which have been reported from Germany (Holtermüller and Wiedemann, 1960; Liebaldt, 1964; Lenz, 1964) or in families of German descent living in North America (Angle, McIntire, and Moore, 1967; Wollin, Binnington, and Partington, 1968; Feingold, O'Connor, and Berkman, 1969). Outside the skull a few cases have had normal skeletons, but most have had either localized bony abnormalities or generalized chondrodysplastic changes.

In 1968 we reported an 8-year-old boy from Canada with a cloverleaf skull and no other bony abnormalities. We also presented limited data on a 3-month-old child from Louisville, Kentucky, whose deformities were probably confined to the skull. In this paper we present $\mathbf{4}$ further examples of the cloverleaf skull syndrome, 3 from Britain and 1 from Canada, all of which had widespread chondrodysplastic changes as well.

\section{Case Histories}

The Bart's specimen Lenz (1964) recognized that one of the photographs shown to illustrate varieties

Received 22 March 1971. of achondroplasia in a long article on pygmies by Gates (1958) was that of a case of the cloverleaf skull syndrome. This photograph was of a specimen in the Pathology Museum of St. Bartholomew's Hospital, London. The origin of the specimen is not known but there is no reason to believe that it was other than Britain. It was taken into the museum some time between 1831 and 1851. Paget described the specimen in the museum's catalogue of 1851 as the 'skeleton of a foetus at about the seventh month showing the effects of hydrocephalus and rachitis'. Bowlby, in 1884, revised the catalogue and described the specimen as the 'skeleton of a foetus, twelve inches in length, showing the condition of the extremities which is typical of cretinism'. In 1929, Shore offered a further interpretation with a description which we quote in full.

\section{Achondroplasia with Hydrocephalus}

'TE 256. The skeleton of a foetus at about the seventh month, showing shortening and thickening of the long bones of the extremities, together with hydrocephalus. The hydrocephalus is of unusual form owing to premature synostosis of a part of the cranial vault. The frontals are widely separated from one another, but are partially fused with the parietals, while the sagittal and lambdoidal sutures are completely synostosed. In the latter situations the bones are thickened, though light and porous, and this has prevented the skull from expanding in the parietal and occipital regions. Expansion has taken place chiefly in the region of the anterior 
fontanelle and between the frontal bones, and also laterally in the parieto-squamosal region, where no synostosis has occurred. The skull has thus assumed a broadly pyriform shape and measures 4 inches from base to vault. The parietal bone is thrown backwards into a vertical position. The posterior fontanelle is unclosed and its edges are everted, roughened and prominent. In the lateral regions of the skull the bones are set apart and bowed by the pressure of the hydrocephalic fluid; thus the squamous portion of the temporal looks vertically downward, as does the external auditory meatus. The orbits are much encroached upon by the bulging of the skull, which affects their upper and outer walls. There is no clear evidence of shortening or premature synostosis of the basis cranii.

'The total length of the skeleton is 12 inches, but some of this is due to the upward expansion of the skull. The vertebral column is natural; the ribs are thickened and unnaturally short. Both the upper and lower extremities are somewhat stunted. The arms measure but 31 inches from the shoulder to the fingertips and do not reach beyond the

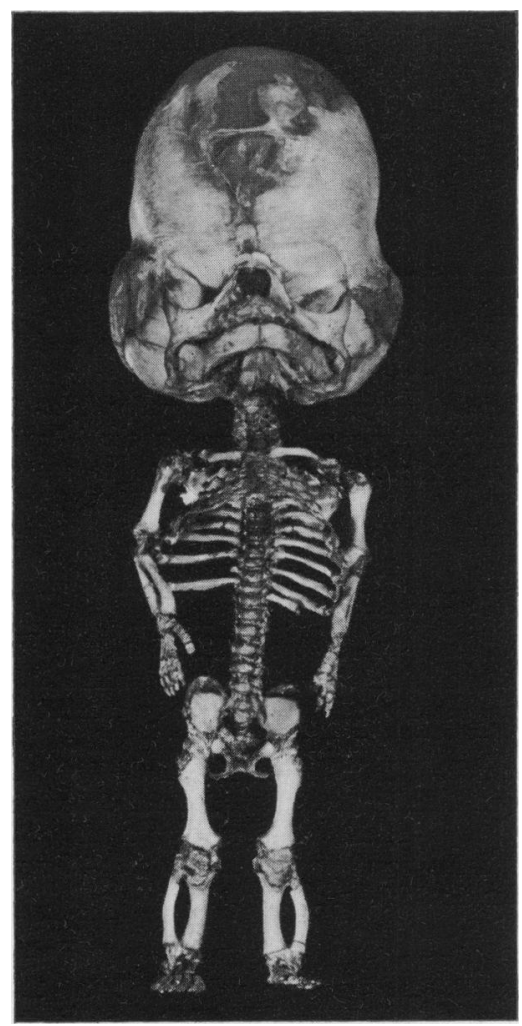

FIG. 1.-Photograph of the Bart's specimen. The skull is large in comparison to the remainder of the skeleton and is typically 'cloverleaf'. Note the short thick bones with curved radii and fibulae, normal clavicles, narrow thoracic cage, short extremities, and relatively normal length of spine. anterior superior spines of the ilia. The lower limbs, from the head of the femur to the heel, show a similar measurement. The total length of the spine is $4 \frac{1}{2}$ inches. The diaphyses of all the long bones of the limbs are well ossified, thickened and heavy, but only of some two-thirds the length natural to a seven month foetus. Some, such as the femora and fibulae, are unnaturally curved, as well as thickened. The epiphyses, owing to the mode of preparation, are so shrunken that their condition cannot be determined. There is no beading of the ribs. The clavicle alone of the limb-bones is natural in length and thickness.

'It is probable that the condition of the long bones of the limbs is due to a slight degree of achondroplasia.'

Photographs and $x$-rays of the specimen are shown in Fig. 1 to 4 .

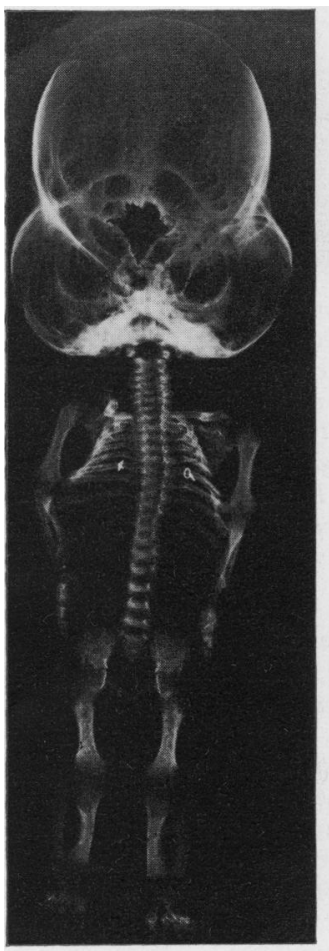

(a)

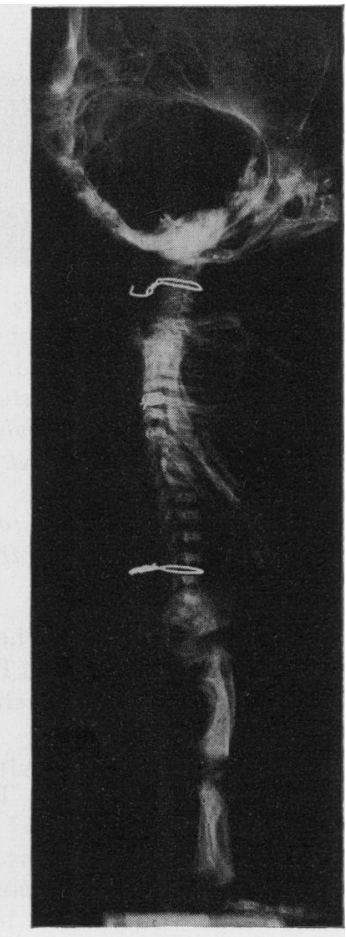

(b)
Fig. 2.-X-rays of the Bart's specimen. Visible ossification of epiphyses at the ends of all long bones is absent. Metacarpals, metatarsals, and associated phalanges are well ossified. Small spurs of periosteal bone project at the lateral aspects of the proximal end of the humeri and distal ends of the femora. The proximal segments of the extremities are proportionately shorter than the distal segments. The iliac wings are small, the roof of each acetabulum is flat. The length of the spine is relatively normal compared to the short upper and lower exremities. The intervertebral disc spaces are correspondingly increased. The interpedicular distance in the lumbar vertebrae gradually narrows from $L 1$ to $L 5$. 


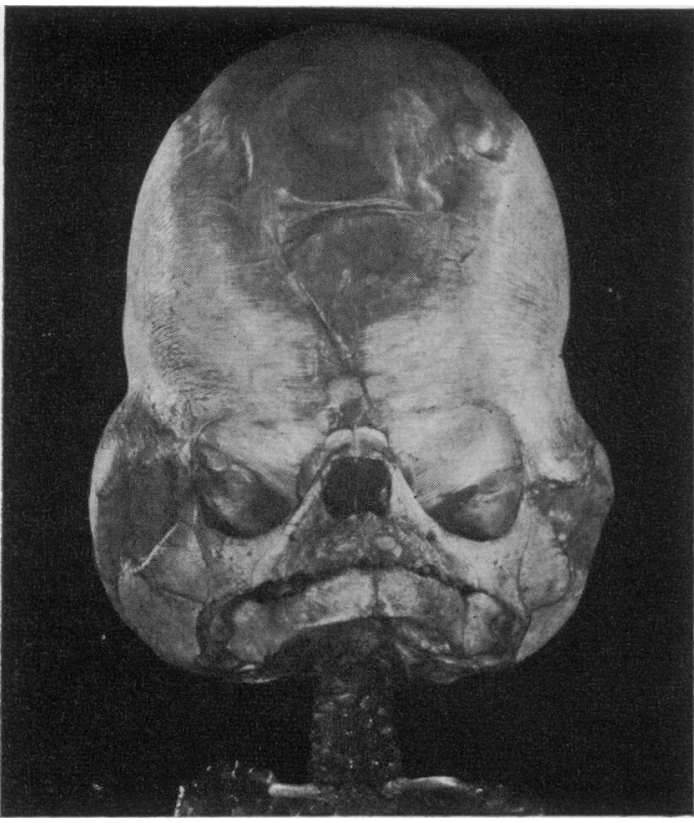

FIG. 3.-Photograph of the skull and facial bones of the Bart's specimen. The trilobed contour of the cranial vault is the outstanding feature; the superior lobe is the largest. Ossification of the vault is incomplete. The orbits are shallow, particularly at the superior orbital margins. The maxillae and mandible are small compared to the size of the nasal bones. The anterolateral fontanelle (pterion) extends forward to the lateral margin of each orbit.

The Derby cases. These two cases came to light through Dr. Whitelaw and Dr. Whitaker who diagnosed them in retrospect when shown $x$-rays of our cases of 1968.

Both patients were girls from the same sibship. The parents were unrelated. The first 3 children in the family (a boy born in 1957 and two girls born in 1960 and 1961 respectively) were normal and there had been no miscarriages. The mother was aged 33 and 35 years, respectively, when her abnormal children were born; the father was a year younger. There were no abnormalities discovered in the rest of the family except for a cousin of the mother who had died at the age of 15 months with mental retardation and an enlarged head; no further information could be obtained about this child. Both sides of the family were English and had lived in England for at least 4 generations; the mother's maiden name was Wolfe which is often regarded as of German origin.

Case 1 (date of birth, 11 August 1965). During the pregnancy the mother was well until the 31st week when she went into labour. She was thought to have hydramnios; no fetal parts were felt and no fetal heart

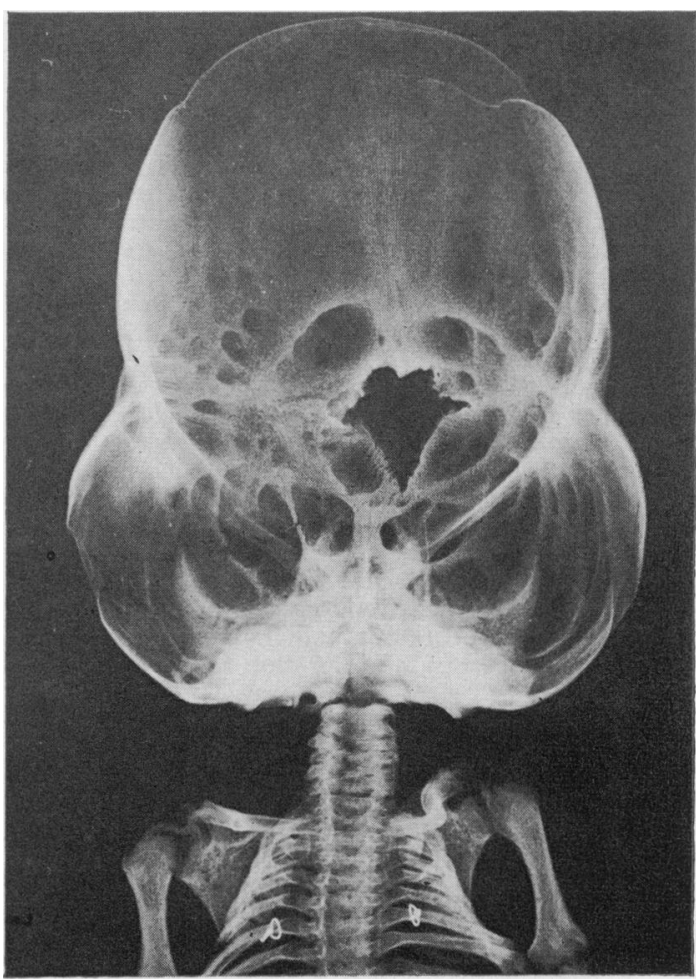

FIG. 4.-X-ray of the skull of the Bart's specimen: anteroposterior view. Two struts of thickened bone, one on each side, appear to compress the vault and produce the trilobed deformity. A large irregular defect is present in the posterior aspect of the vault at the junction of the three lobes posteriorly; it is believed to represent the posterior fontanelle (lambda).

was heard. About $3700 \mathrm{ml}$ amniotic fluid were released after artificial rupture of the membranes. An $x$-ray showed the abnormal fetus. The first stage of labour lasted 27 hours, the second lasted 10 minutes, and the baby was born spontaneously as a vertex delivery. The placenta was normal and weighed $568 \mathrm{~g}$. The baby was a female child weighing $2.02 \mathrm{~kg}$ who died at the age of 5 minutes. No clinical description was recorded beyond the statement that the child had 'hydrocephalus and achondroplasia'. $X$-rays were taken after death (Fig. 5, Case 1).

Case 2 (date of birth, 26 February 1969). In this pregnancy the mother was well until the 38th week when she developed swelling of the ankles and slight hypertension. She was admitted to hospital and $x$-ray showed the abnormal fetus presenting as a breech. Labour started spontaneously 5 days later. The first stage lasted 25 hours and the fetal heart was heard. During the second stage an episiotomy was carried out and the legs and trunk were delivered. The after- 

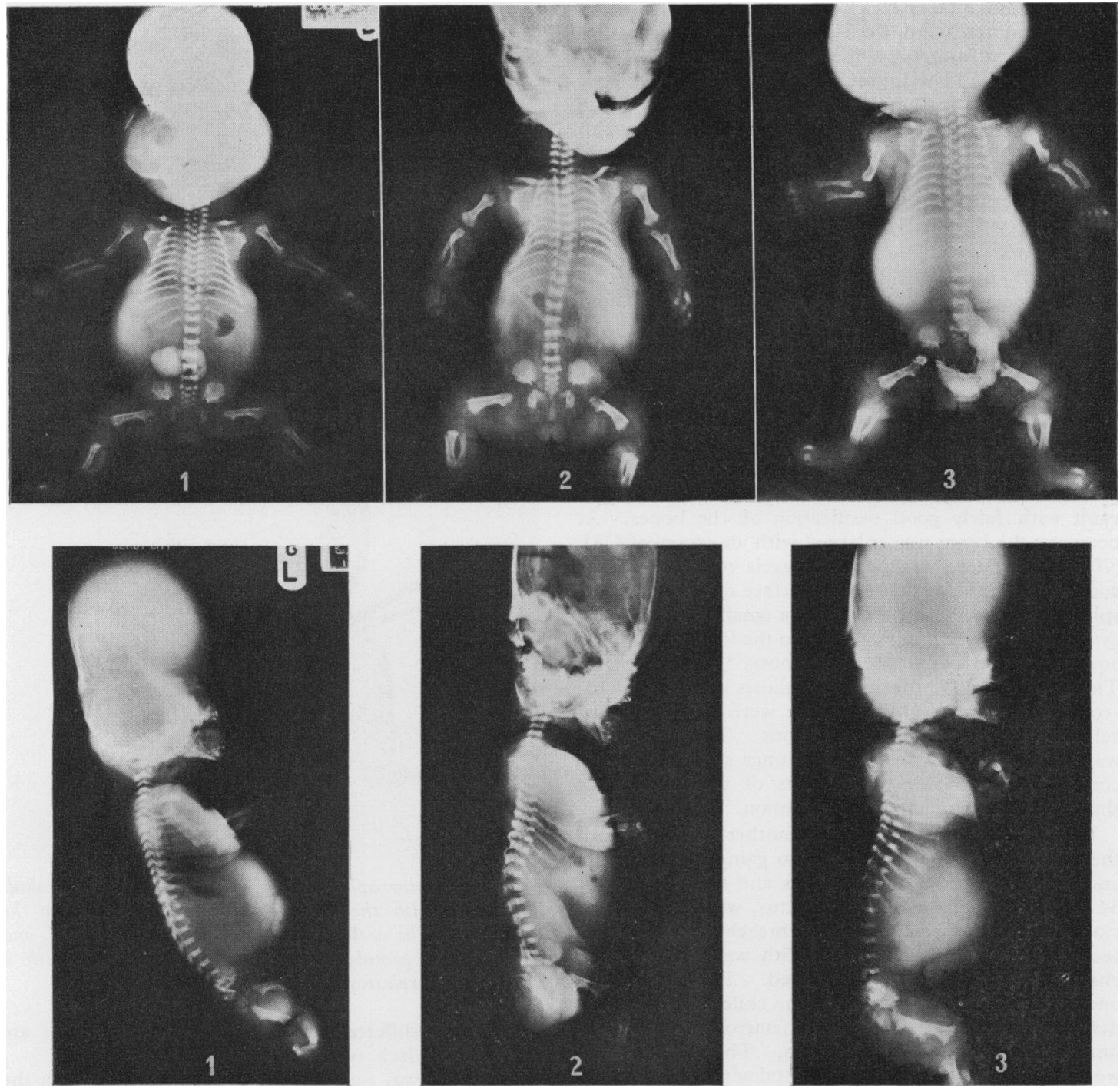

FIG. 5.-Cases 1, 2, and 3. Anteroposterior and lateral x-rays showing the general topography and skeletal changes. Note the narrow airless thoraces, short curved limbs, marked platyspondyly with greatly increased intervertebral disc spaces, micromelia affecting the proximal limb segments more than the distal, broad iliac wings, flat acetabula, and broad pelves. The trilobed contour of the cranial vault in each patient is evident.

coming head was delayed at the pelvic brim. It was not possible to drain the head by needle because of the hardness of the bones so a craniotomy and cranioclasty were performed. The baby, a girl weighing $3 \cdot 1 \mathrm{~kg}$, was dead at birth. The placenta was normal macroscopically and microscopically and it weighed $657 \mathrm{~g}$. The only clinical description was 'hydrocephalus with achondroplasia'. Further $x$-rays were taken after death (Fig. 5, Case 2).

\section{The Kingston case}

Case 3 (date of birth, 1 August 1969). The mother was aged 37 years and the father 46 years at the time the child was born and they were unrelated. The mother's family had all originated from Germany, emigrating to the U.S.A. three generations previously; the mother's parents still spoke German as their native tongue. The father's family had emigrated to Canada from Northern Ireland three generations previously. 
In 1958 the mother had had an abortion at 12 weeks. In 1959, in the 42nd week of her second pregnancy, the baby died in utero; labour was induced and a stillborn female child weighing $2320 \mathrm{~g}$ was delivered as a breech; necropsy showed a high ventricular septal defect but no other abnormalities. In 1960 she had an abortion at the tenth week of pregnancy. In 1961, at 42 weeks of pregnancy, she developed severe preeclamptic toxaemia; labour was prolonged but a normal male child weighing $3160 \mathrm{~g}$ was delivered who is still alive and well.

In 1965 her fifth pregnancy was terminated by caesarean section following a failed induction of labour at 42 weeks. Antenatal $x$-rays had shown an abnormal fetus with hydrocephalus. A male child weighing $4360 \mathrm{~g}$ was delivered. The child had hydrocephalus (head circumference $46 \mathrm{~cm}$ ), a cleft of the posterior half of the palate and bilateral club feet. The Apgar score was 6 one minute after birth: the child's condition deteriorated and he died at 16 hours of age. Pre- and postmortem $x$-rays of the skull showed an enlarged vault with fairly good ossification of the bones. At necropsy the brain was enlarged with an excess of CSF $(700 \mathrm{ml})$. There was polymicrogyria over the frontal cortex on each side; the medial surface of the left hemisphere was absent and there was a small porencephalic cyst in the left occipital region. In the lower part of the aqueduct there was an area of stenosis $3 \mathrm{~mm}$ in length. The aqueduct was broken up by gliosis into two microscopic ductules: in addition there were free ependymal cells and some swelling of the axons. The cerebellum was normal though small. The lungs showed obvious congestion and oedema. Sections of the long bones showed normal enchondral ossification.

In the present pregnancy the mother was well until the 33 rd week when she started to gain weight rapidly and developed oedema of the legs and feet. $X$-ray at 34 weeks showed the abnormal fetus, with an enlarged cloverleaf skull, presenting as a breech. A caesarean section was carried out in the 35 th week and a male child weighing $3240 \mathrm{~g}$ was delivered. The Apgar score one minute after birth was 4 . The child was obviously deformed with a trilobed skull, narrow chest, small limbs, and 'trident-shaped' hands. The external ears were rotated into a position horizontal with the shoulders by the huge lateral expansions of the skull (Fig. 6). The infant was in marked distress with gasping respirations, a weak grunting cry, and numerous rales and rhonchi in the chest. The heart rate was $\mathbf{4 0}$ per minute. The child's condition deteriorated and he died at the age of 60 minutes. $X$-ray studies were made after death (Fig. 5, Case 3, and Fig. 7).

At necropsy the lungs showed pulmonary oedema, congestion, interstitial perivascular haemorrhage, and some intra-alveloar haemorrhage. There was obvious pulmonary collapse with poor aeration; the alveolar epithelial cells were cuboidal. The cartilaginous plates of the major bronchi showed large cells with little intercellular substance. This pattern was reminiscent of that found in hypoplastic lungs secondary to congenital diaphragmatic hernia; presumably in both conditions

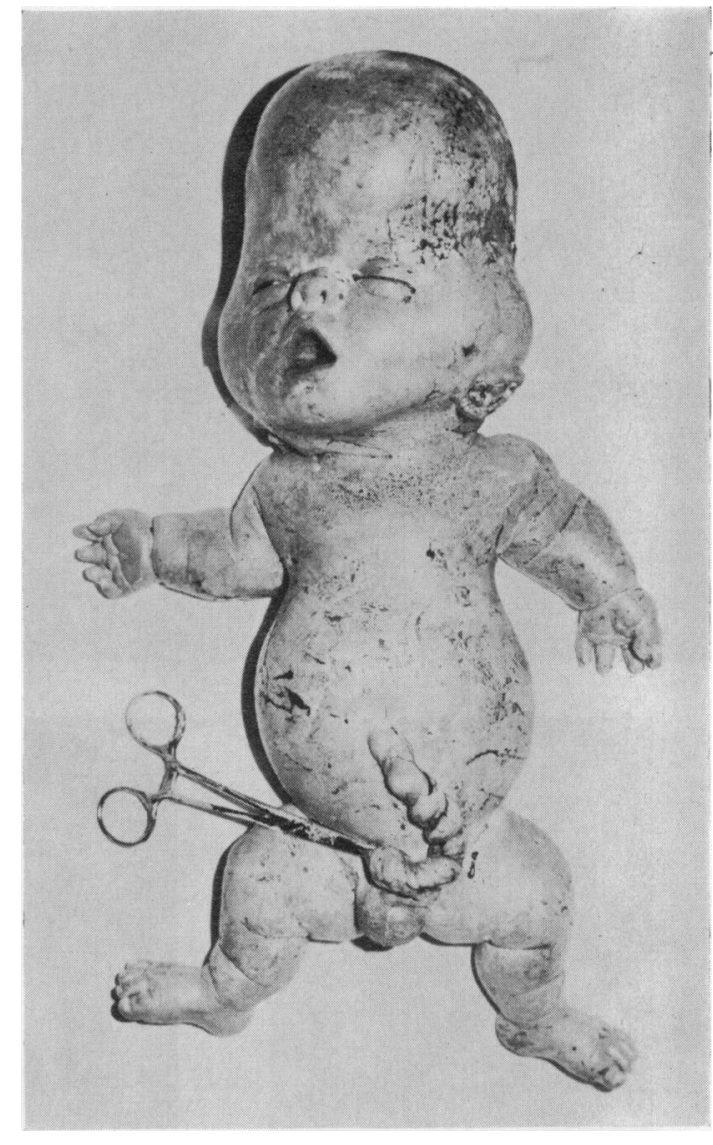

Fig. 6.-Photograph of Case 3 after death. The skull is trilobed, with the ears depressed and parallel to the shoulders. The neck is short, the thoracic cage small, and the abdomen protuberant. There is micromelia with a relatively normal trunk length.

growth and differentiation of the bronchial walls are impeded by lack of space.

The skull was found to be enlarged, flattened in the anteroposterior diameter, broadened from side to side, and of more than usual height. A horizontal constricting band of dense membranous bone passed from the frontal to the occipital region dividing the cranial vault into one superior and two inferior lobes giving the cloverleaf appearance. The superior lobe was covered by unossified membrane; the inferior lobes were covered by a thin shell of membranous bone. There was an irregular defect in the occipital bone above the foramen magnum covered by skin, dura, and arachnoid; no brain herniated into this defect.

On opening the skull the superior lobe was found to contain both cerebral hemispheres except for the temporal lobes which were grossly expanded and occupied the inferior lobes below the constricting band. No vascular malformations were seen on the surface of the brain 


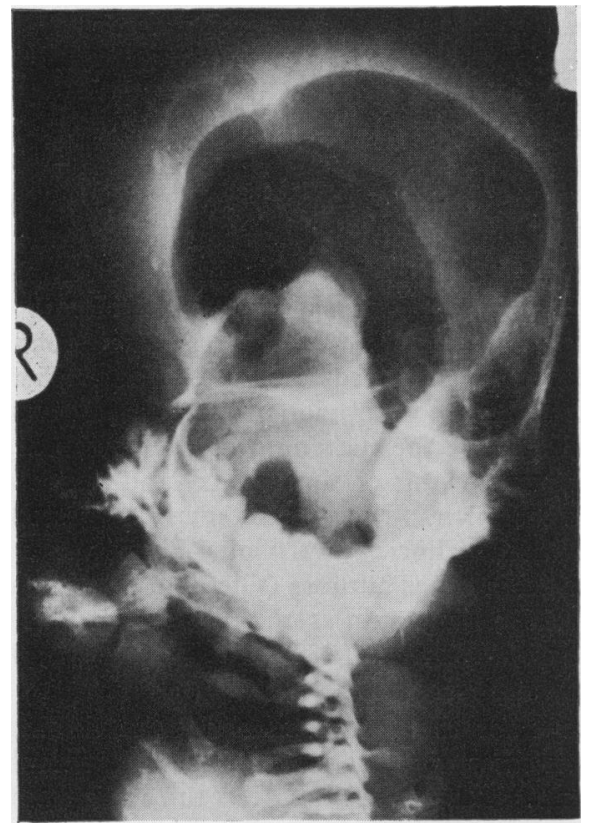

FIG. 7.-Case 3. Ventriculogram performed immediately after death: right lateral view. The superior cranial expansion contains much of the cerebral hemispheres occupied by grossly dilated lateral ventricles. The inferior expansion contains the left temporal lobe with a grossly dilated left temporal horn. The right lateral ventricle was even more dilated.
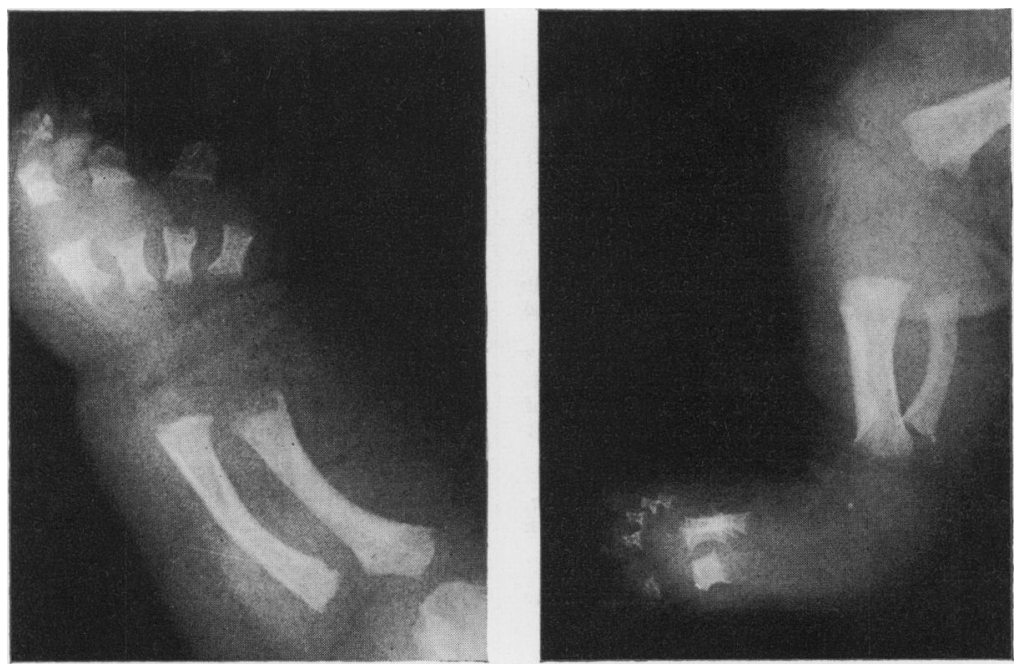

or in its membranes. In attempting to remove the brain the thin cerebral mantle ruptured and a large amount of cerebrospinal fluid escaped. The brain was soft and friable and did not retain its original contour on fixation.

The base of the skull showed the gross expansion of the middle cranial fossae which displaced the petrous portions of the temporal bones posteriorly and parallel to the margins of the foramen magnum. The posterior fossae were small, only 5 to $6 \mathrm{~mm}$ in depth, due both to the displaced petrous temporal bones and marked basilar invagination of the cervical spine into the margin of the foramen magnum. The foramen magnum was small but not deformed.

After fixation the brain weighed $562 \mathrm{~g}$. There was hypoplasia of the cerebellum and the brainstem and failure of differentiations of the tectal plate. The cerebellar hemispheres were separate and there was no evidence of development of the vermis. The lateral and third ventricles were grossly dilated. The aqueduct was enlarged close to its opening into the third ventricle, but more posteriorly it was of normal calibre. Microscopically there was some focal periependymal gliosis with granular calcific deposits, but it was lined by normal ependymal cells. The fourth ventricle was normal in size. The medulla oblongata was displaced caudally into the upper cervical spine by the basilar invagination of the skull.

Sections taken from various regions of the skeleton showed abnormal enchondral ossification particularly in the long bones of the extremities. The zone of provisional cartilage showed inadequate orientation of the cartilage cell columns which were either distorted or poorly formed. The vertebral pedicles, though less severely affected, were the seat of identical changes.

FIG. 8.-Case 3. Radiographic details of the extremities show characteristic concave irregular metaphyses with periosteal overgrowth of bone at the periphery. The long bones of the hand and foot are very short and broad. 
The spinal canal was distorted into a typical triangular shape.

\section{Discussion}

The radiological appearances of the skulls of all our cases correspond with those reported by others in patients with the cloverleaf skull syndrome. Outside the skull, all four cases had micromelic dwarfism with short bowed tubular bones, and flared metaphyses, obvious flattening of the vertebral bodies, and severe narrowing of the chest; death occurred at or soon after birth. The histological findings in one case showed improper endochondral ossification. Formerly these cases would have been classified as fetal achondroplasia or chondrodystrophy, and this, with hydrocephalus, was the diagnosis in the Bart's specimen (Shore, 1929; Gates, 1958), the two Derby cases, and some others reported in the literature (see Table). However, it is becoming increasingly clear that the name achondroplasia has been loosely applied to a variety of unrelated disorders for which strict diagnostic criteria are only now emerging (Carter, 1969; Rimoin et al., 1970). Recent evidence suggests that even the generally accepted histological appearances of 'classical' achondroplasia may be incorrect because they were derived from patients with other diseases (Rimoin et al., 1970; Ponsetti, 1970).

In 1967, Maroteaux, Lamy, and Robert argued on clinical, radiological, and genetic grounds that the conditicn known as fetal chondrodystrophy or congenital achondroplasia was distinct from classical achondroplasia. In the former condition they emphasized the severity of the bony changes, similar to but more obvious than those of classical achondroplasia, the flattening of the vertebrae, the extreme narrowing of the thorax, and death at or soon after birth. Maroteaux et al. suggested the name thanatophoric dwarfism. Subsequent case reports from other authors (Giedion, 1968; Langer et al., 1969; Huguenin et al., 1969; Keats, Riddervold, and Michaelis, 1970; Kaufman et al., 1970) strongly support this view.

Except for the cloverleaf skull, the findings in our own cases meet all the criteria of thanatophoric dwarfism. Maroteaux has seen the radiographs of

\section{TABLE}

Some Characteristics of Patients with 3 Types of Cloverleaf Skull

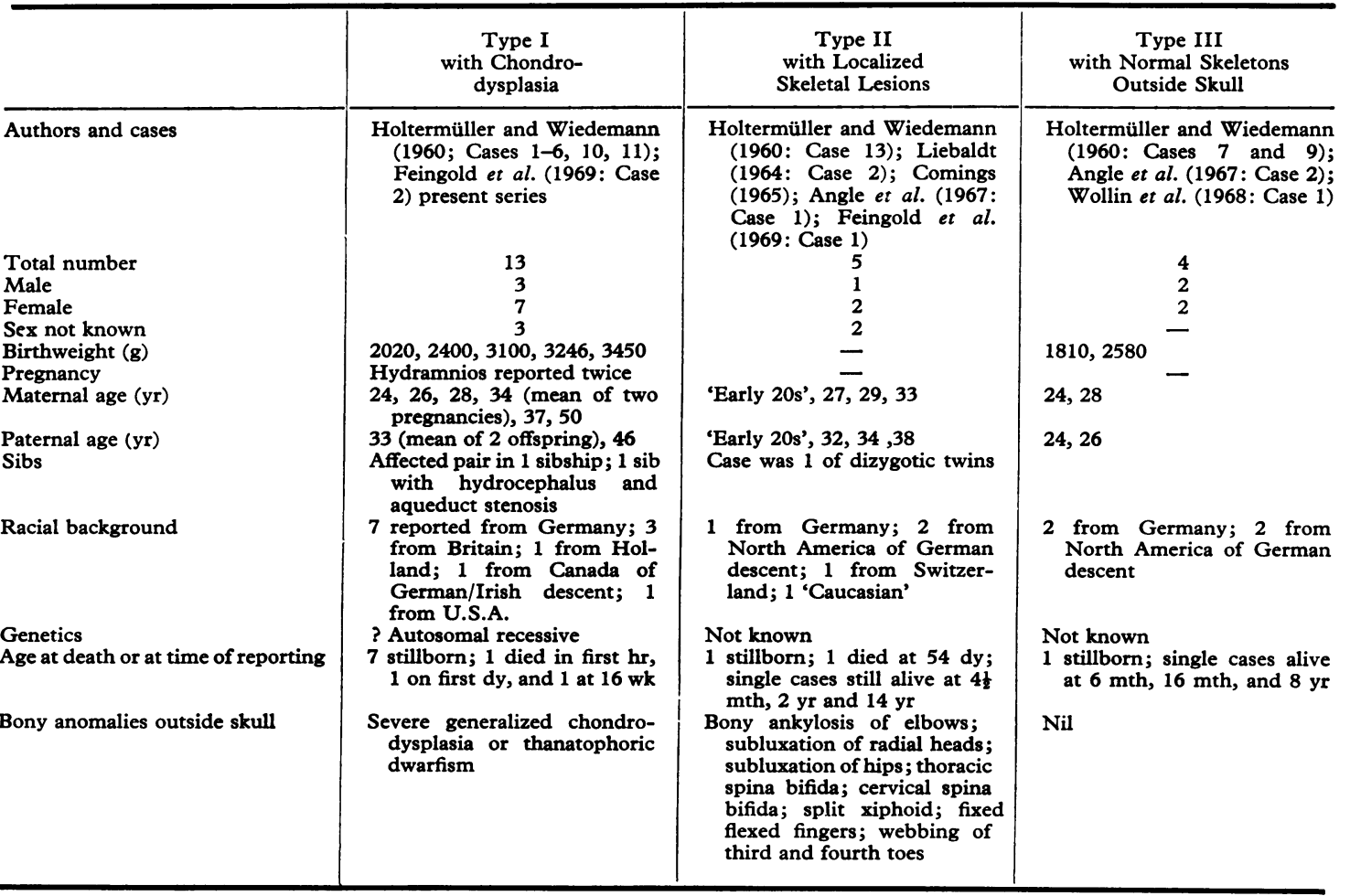


the Kingston case and discussed them personally with one of us (F.G-C): he agrees that, outside the skull, the appearances are those of thanatophoric dwarfism.

It is of great interest that a male sib of the Kingston case had died soon after birth from hydrocephalus apparently due to aqueduct stenosis. At least one form of this disorder is inherited as an X-linked recessive (Edwards, Norman, and Roberts, 1961). One might have postulated that, in the Kingston case, the cloverleaf skull was due to aqueduct stenosis occurring in a child with thanatophoric dwarfism. However, no trace of aqueduct stenosis was found at necropsy. Furthermore, it seems unlikely that all our 4 cases and the 9 others published with the same combination of lesions represent the chance association of two different rare disorders but rather that they are, in some way, related. We think that a cloverleaf skull may well be a previously unrecognized feature of thanatophoric dwarfism.

Burkhardt (1970) has recently reviewed the cloverleaf skull syndrome and he concludes that the cloverleaf deformity is due to morphogenetic forces superimposed on a basic chondrodysplastic process. He believes that the main factor is improper endochondral ossification leading to foreshortening of the base of the skull. The frontoparietal growth of the fetal brain is hampered and it enlarges upward. The lateral expansions of the brain and skull are explained by gross increases in the volume of the temporal lobes due to obstruction of CSF circulation in the lateral ventricles. Early intracranial hypertension may also lead to increased vascularization of the diploë accounting for the haemangiomatous appearance of various skull bones found in some cases. This speculation is quite plausible, but it fails to account for those cases with cloverleaf skulls but without generalized chondrodysplastic skeletal changes. We are equally unable to explain this discrepancy short of postulating a localized chondrodysplastic lesion in the skull in this latter group of patients.

On reviewing our cases and 21 others, we are led to believe that there are at least 2 , and possibly 3, distinct syndromes in patients with the cloverleaf skull deformity (see Table). In the first syndrome, Type I, the cloverleaf skull is associated with thanatophoric dwarfism. In the second syndrome, Type II, there are bony lesions outside the skull, but these are localized, not generalized; death may occur at or before birth but usually the child survives the newborn period and may live for several years. In the third syndrome, Type III, the prognosis is similar to
Type II but the skeleton outside the skull is normal. The distinction between Type II and Type III seems less justifiable on present evidence than between Type I and Type II.

Enough information was available to assign 22 of the 27 cases reviewed to one or another Type with a fair degree of certainty: the 5 unassigned cases probably belong to Type II or III. No case was found with both generalized chondrodysplastic changes and a localized skeletal lesion. Type I seemed the most homogenous group with only one anomalous case. This was a boy reported by Vrolik in 1849 (Case 1 in Table I of Holtermüller and Wiedemann, 1960), who, to judge from the author's description and the artist's drawing, undoubtedly had both a cloverleaf skull and thanatophoric dwarfism but who lived to the age of 16 weeks.

Some characteristics of these three Types of cloverleaf skull syndromes are shown in the Table. The amount and type of data on each case vary and, in sum, are not yet sufficient to make meaningful inferences about aetiology.

The occurrence of affected sibs in the Type I syndrome is reported here for the first time and raises the possibility of an autosomal recessive type of inheritance. If our cases are accepted as examples of thanatophoric dwarfism, then this suggests that thanatophoric dwarfism may be similarly inherited. The preponderance of cases of all Types reported from Germany or from families of German descent supports a genetic rather than a teratogenic aetiology; of course the racial distribution may also be biased due to the way cases have come to light.

We wish to thank Dr. A. G. Stansfeld of the Department of Pathology, Mr. J. L. Thornton of the Medical Library and the Department of Medical Illustration, all of St. Bartholomew's Hospital, London, for their help in the study and presentation of the 'Bart's specimen'; Dr. R. A. J. Whitelaw and Dr. R. Whitaker of Derby for permission to publish their cases, Dr. S. W. George of Kingston for permission to publish his case, and Dr. C. S. Houston of the University of Saskatchewan for comments.

\section{REFERENCES}

Angle, C. R., McIntire, M. S., and Moore, R. C. (1967). Cloverleaf skull: Kleeblattschädel一deformity syndrome. American fournal of Diseases of Children, 114, 198.

Bowlby, A. A. (1884). A Descriptive Catalogue of the Anatomical and Pathological Museum of St. Bartholomew's Hospital, vol. II, p. 17. Churchill, London.

Burkhardt, L. (1970). Pathologische Anatomie des Schädels, p. 115. Springer, Berlin.

Carter, C. O. (1969). Diastrophic dwarfism. Developmental Medicine and Child Neurology, 11, 247.

Comings, D. E. (1965). The Kleeblattschădel syndrome-a grotesque form of hydrocephalus. Fournal of Pediatrics, 67, 126. 
Edwards, J. H., Norman, R. M., and Roberts, J. M. (1961). Sexlinked hydrocephalus. Archives of Disease in Childhood, 36, 481

Feingold, M., O'Connor, J. F., and Berkman, M. (1969). Kleeblattschädel syndrome. American Fournal of Diseases of Children, 118, 589.

Gates, R. R. (1958). The African pygmies. Acta Geneticae Medicae et Gemellologiae, 7, 159.

Giedion, A. (1968). Thanatophoric dwarfism. Helvetica Paediatrica Acta, 23, 175.

Holtermüller, K., and Wiedemann, H. R. (1960). KleeblattschädelSyndrom. Medizinische Monatsschrift, 14, 439.

Huguenin, M., Godard, C., Ferrier, P. E., and Bamatter, F. (1969) Two different mutations within the same sibship: thanatophoric dwarfism and Ullrich-Feichtiger syndrome. Helvetica Paediatrica Acta, 24, 239.

Kaufman, R. L., Rimoin, D. L., McAlister, W. H., and Kissane, J. M. (1970). Thanatophoric dwarfism. American fournal of Diseases of Children, 120, 53.

Keats, T. E., Riddervold, H. O., and Michaelis, L. L. (1970). Thanatophoric dwarfism. American fournal of Roentgenology, Radium Therapy, and Nuclear Medicine, 108, 473.

Langer, L. O., Spranger, J. W., Greinacher, I., and Herdman, R. C. (1969). Thanatophoric dwarfism. Radiology, 92, 285.

Lenz, W. (1964). Anomalien des Wachstums und der Körperform. In Humangenetik, vol. 2, p. 79. Ed. by P. E. Becker. Thieme, Stuttgart.

Liebaldt, G. (1964). Das 'Kleeblatt'-Schädel-Syndrom, als Beitrag sur formalen Genese der Entwicklungsstörungen des
Schädeldaches. Ergebnisse der allgemeinen Pathologie und pathologischen Anatomie, 45, 23.

Maroteaux, P., Lamy, M., and Robert, J. M. (1967). Le nanisme thanatophore. Presse Médicale, 75, 2519.

Paget, J. (1851). A Descriptive Catalogue of the Anatomical Museum of St. Bartholomew's Hospital, vol. II, p. 210. Churchill, London.

Ponsetti, I. V. (1970). Skeletal growth in achondroplasia. Fournal of Bone and foint Surgery, 52-A, 701.

Rimoin, D. L., Hughes, G. N., Kaufman, R. L., Rosenthal, R. E., McAlister, W. H., and Silberberg, R. (1970). Endochondral ossification in achondroplastic dwarfism. New England fournal of Medicine, 283, 728.

Shore, T. H. G. (1929). A Descriptive Catalogue of the Pathological Museum of St. Bartholomew's Hospital Medical College, vol. II, p. 1632. Adlard, London.

Vrolik, W. (1849). Tabulae ad illustrandem Embryogenesin Hominis et Mammalium, tam Naturalem quam Abnormem, Fig. 35, 36. G.M.P. Londonck, Amsterdam.

Wollin, D. G., Binnington, V. I., and Partington, M. W. (1968). Cloverleaf skull. Fournal of the Canadian Association of Radiologists, 19, 148.

Correspondence to Dr. M. W. Partington, Department of Paediatrics, Queen's University, Kingston, Ontario, Canada. 